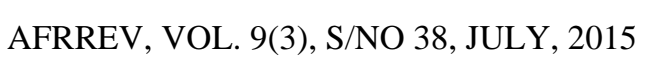 \\ African Research Review
}

An International Multidisciplinary Journal, Ethiopia

Vol. 9(3), Serial No. 38, July, 2015:62-74

ISSN 1994-9057 (Print) ISSN 2070-0083 (Online)

DOI: http://dx.doi.org/10.4314/afrrev.v9i3.6

\section{Effective School Management and Supervision: Imperative for Quality Education Service Delivery}

\author{
Agih, A. Allen \\ Department of Educational Foundations \\ Faculty of Education \\ Niger Delta University, Wilberforce Island \\ Bayelsa State, Nigeria \\ Email: allen.agih@ndu.edu.ng
}

\begin{abstract}
To provide quality education requires effective management of the human and material resources in the industry. Supervision which is a component of education administration is equally fundamental if the goals of the system will be realized. This paper therefore examines the twin concepts of school management and supervision as the vital factors in providing quality education services. The paper advocated for school administrators to have the required qualification and experience to function optimally. Also, managers of the education industry were advised to attend conferences, seminars and workshops to enhance their skills in school management and supervision among others.
\end{abstract}

\section{Introduction}

Education in all countries of the world is seen as the corner stone of development. It forms the basis for literacy, skills acquisition, technological advancement as well as 
the ability to harness the natural resources of the environment for development. To be able to actualize this, the school organization must be properly managed.

The School is an organization of complex activities which are carried out by people and are coordinated by different persons. Thus, management is necessary in school to co-ordinate the various activities of the units for goal achievement. Management in school entails working with and through teachers, non teaching staff and pupils or students to get things done effectively. School management has its attention primarily on the school. It is more concerned with the institution, its goals, policies and execution of these policies. In school management, the primary aim has to do with the improvement of teaching and learning, and all the activities of the school. The functions of management in school are performed by the schools heads (i.e. head teacher/principal) known as the school manager.

A school manager is described as an executive head of his organization. He/she is a coordinator who has to organize activities in such a way that things work smoothly, quickly and effectively. The education manager is described as the individual in a school setting who directs the affairs of the school in such a way as to achieve its primary goals and objectives. He/she is involved in effective planning, organizing, supervision, controlling and evaluation. Therefore, for a school manager to successfully accomplish the set objectives, he has to work with other people within the school system and be able to inspire them to work co-operatively with him so as to achieve the educational objectives.

Sidho (2002) highlighted some principles that can be of help in the achievement of school objectives. These include consistency with the philosophy of education, democratic approach, optimum contribution by all, respect for individualities, due importance to different programmes, and optimistic outlook.

\section{Function of a School Manager}

The purpose of school management is to enable members of staff of the school and the students to work together with the head-teacher of the school as a team in order to achieve the desired goals and objectives of the school. The school manager is the person responsible for coordinating the activities of the school, using resources at his disposal in such a way that the school's objectives are achieved. He is essentially an organizer and implementer of plans, policies and programmes meant for specific educational objectives. Jaiyeoba (2003), highlighted some of the functions performed by school the manager (principal) as planning, organizing, coordinating and directing.

Planning: The school manager prepares a plan that will embrace the subjects in the school curriculum, the number of students, the number of classes, the number and qualifications of teachers to teach the various subjects as well as the instructional materials that will be required for effective teaching. He request for personnel ahead 
of time and ensures that the time-table for instructions is prepared in such a way that clashes are avoided.

Organizing: The school manager organizes both the human and material resources. He organizes the work in the school into units with each unit manned by a specialist. $\mathrm{He}$ assigns tasks to the administrative staff and also organizes instructional materials that are necessary to enhance student learning.

Coordinating means the tasks of uniting and correlating all activities of the school. The school manager coordinates all activities of the various units within the school. Since the teachers are interdependent, it is the duty of the Principal to coordinate their activities.

Controlling is the means by which the manager sees that things are done according to laid-down rules and regulations. In the school, the manager has to ensure that teachers perform their duties as required, which can be done through effective supervision, making corrections where necessary.

Directing: The school manger is expected to provide effective leadership. He accomplishes this task by stimulating his staff to perform and guiding them as to what to do. He also guides the performance of the students, by telling them what to do on a daily basis through announcements at school assemblies.

\section{Operational Areas in the School Management}

The school manager, in an attempt to carry out the functions earlier discussed, performed a variety of tasks. These tasks or operational areas of management, according to Campbell, Bridges and Nystrand (1977), are grouped into the following six categories:

1. School-Community Relations: The school as an organization cannot be divorced from its environment and this is the reason why the school managers have to develop and administer a culture for the participation of parents and the community in school affairs. Time must always be created to receive and interact with parents who visit the school or who are invited to the school. Such parents should be accorded the highest respect. Parents' complaints should be taken seriously and handled with respect and a sense of concern.

2. Curriculum and Instruction: This is the core area of the school system i.e. the essence of teaching -learning process. It is therefore crucial that the school managers should pay adequate attention not only to the planning of the curriculum but also to the effectiveness of the delivery of instruction and also, the execution of the instructional programmes. Managers have to create conductive working environment for teaching and learning. This, they can 
achieve through dynamic leadership, provision of material and instructional resources, provision of co-curricular activities for the students, motivation of staff, innovative instructional methodology and good human relations.

3. Staff-Personnel: This implies provision of personnel needed in carrying out programmes of instruction and pupils personnel i.e. (teaching and nonteaching staff). The school manager should provide appropriate stimulation and encouragement to staff members so as to retain them on the job and at the same time get them perform their tasks to the maximum benefits of the organization. It is important for the school manager to provide orientation exercise for newly employed staff, and at the same time, do a proper placement of these staff members so as to provide a source of satisfaction for them and thereby retain them on the job.

4. Students/Pupils-Personnel: This involves the services rendered to students that compliment regular classroom instruction such as taking pupils inventory, organizing the pupils provision of social workers and guidance counselors to help the students in both their academic and social lines. There should be accurate data on pupils' enrolment, so that the well being of the pupils would be taken care of. Also counseling services should be provided as they help in minimizing discipline problems in schools. The school managers apart from the provision of the welfare services, should also encourage co-curricular activities such as recreational activities, participation of students in different clubs such as Boys Scout, farmers' club, JETS club, etc

5. Physical Facilities: It consists of the school buildings, school grounds, equipment and other education facilities that are provided in the school which aid the stimulation of teaching-learning process. It is usually assumed that effective learning can occur regardless of the type of school facilities provided. Ill-ventilated classroom cannot support optimum learning and a pleasant school layout produces measures of psychological effects on the learner. The manager must make sure that the buildings are kept safe for the students' use and that they are under good sanitary conditions. Worn-out equipment should be repaired, leaking roofs and chairs should be repaired as well. The whole school should be made attractive so as to boost the morale of the teachers and students in the school.

6. Finance and Business Management: It involves making budget for the school, securing revenue from the government or through other sources, managing expenditure, and directing non-teaching personnel. The school manager should prepare the budget, secure revenue for the school and also 
use the fund at his disposal judiciously. He must also provide a proper accounting system for the money collected in the school.

7. General Duties: The school head is expected to summon staff meetings in order to provide a forum for direct communication with both teaching and non-teaching staff. This is important so that the teaching and learning goals could be achieved. The school principal has the responsibility for projecting the image of the school through functions like sporting events, literary and cultural displays by the school etc.

\section{School Management for Quality Education Service Delivery}

Education quality is becoming increasingly important for those who are involved in it either directly or indirectly, and for those who use its services. Access to education and quality education are to be regarded as mutually dependent and individual needs and rights. This is primarily achieved by developing creativity, civil and democratic values, as well as by knowledge, ability and skills needed for everyday and professional life. Basic education is not sufficient or complete, and therefore should be considered only as a basis for learning that needs to be used all lifelong. Lifelong learning for all has become one of the pillars of development.

The UNESCO (2012) report highlighted indices of quality education. Some of them are:

i. Quality learners: Are learners healthy, well-nourished and ready to participate and learn, supported in learning by their families and communities?

ii. Quality learning environment: Is the environment healthy, safe and protective and gender sensitive, and provides adequate resources and facilities?

iii. Quality content: Is the content reflected in relevant curricula and materials for the acquisition of basic skills and knowledge?

iv. Quality processes: Processes through which trained teachers use childcentered teaching approaches in well-managed classrooms and schools and skill assessment to facilitate learning.

v. Quality outcomes that encompass knowledge, skills and attitudes, and are linked to national goals for education.

\section{Other Indicators of Quality in Education}

The system of indicators of quality in education, as well as quality criteria associated with the indicators, help schools to point out the important areas of their own activities - their own advantages and disadvantages and development opportunities. School quality team can debate about representation and development 
of particular aspects and search for method for upgrade and meliorate indicator representation in specific school circumstances.

The indicators are grouped into seven areas with specific topics:

1. Curriculum: Structure of the curriculum (program/goals, tasks, focus on development of functional tasks, focus on students' activities, integration of programs within and between areas).

2. Achievement (evaluated by external, independent agencies) achievement quality compared with the set goals.

3. Teaching and Learning: Teachers work, students' work and experience, meeting the needs of the students, monitoring and evaluating the work of students and teachers.

4. Students' support: Students' personal, social and spiritual growth, progress and achievement monitoring, support in all aspects of learning, progress, students and teachers personal development.

5. School ethos: School policy, school atmosphere and relations, specific goals of each individual school, orientation towards students', teachers and parents satisfaction.

6. Resources: School resources, teachers' professional associates, the principal, their education, teacher team work, cooperation, being open to innovation, material resources and premises, efficient human and material resource.

7. Management: Leadership and quality assurance, approaches to leadership and management.

\section{Some Theories in School Management}

To be able to function effectively, the school manger needs to be abreast of some theories in education management. Some of them are high listed below:

a. Leadership theories

b. Decision making theories

c. Communication theories

d. Conflict theories

e. Motivation theories

f. Human Relation theories

Knowledge and utilization of these theories in all areas of management (public/ private schools and companies) will enhance the job performance of the manager. This will eventually lead to realization of organizational goals and objectives. 


\section{Supervision}

Supervision is an administrative process through which the leader ensures that his subordinates are all contributing towards effective learning process. Hammock and Owing in Nwaogu (1980) stated that supervision attempts to look into the organization of learning programmes, the grouping of pupils, method of evaluating, reporting and determining pupil's progress, the content of the curriculum, the teaching methods, the philosophy and practicing of discipline, the time schedule, place and procedure of staff meetings, procedures used in parents conference, the study and use of the community resources. All these are evaluated and thoroughly discussed in the attempt to improve the learning and growing of the students.

The concept of supervision is one that describes a process that is common to all professions and occupations. No organization can function effectively without it. Supervision is an interaction between at least two persons for the improvement of activity. It is a formative, supportive and developmental process designed to improve and process of guiding encouraging, directing and motivating workers so as to improve their output

\section{Purpose of Supervision}

The purpose of instructional supervision in the school systems according to Nnabuo (1996) are:

(a) To develop educational goals;

(b) To control and co-ordinate educational activities;

(c) To motivate teachers and other staff;

(d) To solve problems in educational organization;

(e) To develop teaching professionalism; and

(f) To evaluate or assess educational outcomes.

In addition, instructional supervision is needed to ensure that each individual teacher within the school system had been performing the duties for which he was scheduled and to improve the effectiveness of teachers so that they could contribute meaningfully to the attainment of the system's goal.

It could be summed up that the purpose of instructional supervision is to improve teaching and learning process for the benefit of the student, teacher and society.

\section{Qualities of a Good Education Manager and Supervisor}

Scholars have identified teacher competence to relate to effective planning, management and evaluation. Lowise Back in Nnabuo (1996) finally came up with some characteristics a good school supervisor must possess. These are: 
1. He/she must adapt at helping young people control themselves and even more adapt at controlling himself;

2. Be a good listener and less talker;

3. Be attuned to the needs of others;

4. Be a good counsellor;

5. Know how to be fair and firm;

6. Lead without appearing to dominate; and

7. Be able to share the process of planning and directing others.

Similarly, Akinade (1996), Peretomode (2003) in Agih (2013) identified some of the qualities of a good school manager as technical skill, human skill, conceptual skill, emotional stability, ability to motivate others, honesty, commitment to duty, clear vision and goal.

\section{What to Supervise}

There are many things to supervise. These include the school programme and resources, assessment of Principals (other head teachers), the teachers, the nonacademic staff, the students/ Pupils, the school plants (facilities and equipment), the school account, the school project and school records. Also, the indicators of quality in education as discussed in the proceeding text are others items to supervise.

\section{Types of Supervision}

Jaiyeoba (2006) categorized supervision under two types:

i. Internal supervision

ii. External supervision

\section{Internal Supervision}

As the name implies, this is the type of supervision carried out by the internal supervisor in the school as the principal, headmaster/mistress, their assistant or the heads of departments. It is also referred to as within school supervision.

An example of effective internal supervision is clinical supervision. This is a clinical approach to school supervision. According to Goldhammer and Krajeweski (1969), clinical supervision refers to a close observation, detailed face-to-face interaction between the supervisor and the teacher with the aim of binding the two in an intimate professional relationship. Clinical supervision is often perceived as a model with certain stages or cycle of phases. In 1969, Goldhammer and his colleague, with the basic ideas they got from Morris Cogan, specified a five stages or cycles of supervision. These are:

a. Pre-observation conference;

b. Observation; 
c. Analysis and strategy;

d. Supervision conference; and

e. Post conference.

\section{External Supervision}

This is the type of supervision carried out by people designed by the Ministry of Education to carryout supervision in schools. This used to be known as inspection. They include those who go by the titles, Chief Inspector of Education, Deputy Inspector of Education, Zonal Inspector of Education, etc.

These are Inspectors who are expected, as their primary responsibility, to inspect schools and work directly with teachers to improve the quality of instruction in school.

\section{Types of External Supervision}

External supervision can further be divided into four main types namely:

i. Full inspection

ii. Follow-up inspection

iii. Partial inspection

iv. Recognition inspection / certification inspection

\section{Full Inspection}

In this type of inspection every aspect of the school is supervised. These include the teaching staff, non-teaching staff, subjects taught in the school, the mode of assessment of students, school records, equipment, school plant, overall organization of the school among others.

It is carried out to ascertain the level of school performance in the aspect of curriculum implementation, distribution of duties, school organization and general discipline in school.

\section{Follow-up Inspection}

This is the supervision carried out to assess the actions taken on the recommendations and suggestion made in the report on the full inspection. It is embarked upon so as to find out if the actions taken are achieving the desired objectives. This type of supervision helps in encouraging the staff to strive for greater professional efficiency. It also helps in stimulating interest for educational development in the students. 


\section{Partial Inspection}

In this type of supervision, the supervisory practice is limited in scope. It does not involve every aspect of the school life neither does it involve a team of experts up to the level of full inspection.

\section{Certificate Inspection}

It is a form of school inspection intended for individual teacher that needs upgrading for one reason or the other. It is useful for confirmation at the appointment at the end of the teachers' probation period. Here, inspectors are not expected to pose themselves as faultfinders or mere critics, but as helpers, advisers and inspires in every possible way to attain desired standard in the school

\section{Recognition Inspection}

Another type of inspection related to certification inspection is recognition. It is a type of inspection that is usually conducted on a young school which, in practice, has had an advisory visit and is now seeking to gain accreditation as centre for public examinations such as the Senior School Certificate Examination (SSCE) and the National Technical Examination (NTCE).

It is designed to assess the standard as well as the preparedness of any institution seeking accreditation to the examinations conducted by public bodies (for example, WAEC, NABTEB, NECO) with a view to recommending them for approval by such bodies.

\section{Stages of External Supervision}

Supervision involves three stages namely:

i. The preparation stage

ii. The real supervision or observation stage

iii. The conference stage

\section{The Preparation Stage}

This is the period prior to supervision. At this stage, the school or person to be supervised is informed. The type of supervision or person to be supervised is informed. The type of supervision to be carried out is communicated so that adequate preparation can be made. Adequate plans for supervision for successful supervision are made at this stage. The supervisor plans for those aspects of the school that would be supervised. 


\section{The Real Supervision or Observation Stage}

This is the stage at which the real observation is carried out. The supervisor(s) visit the school/classroom and observe the situation. Those aspects to be supervised as previously planned would be supervised and notes would be taken.

\section{The Conference Stage}

This is the last stage. At this stage, meeting is held with those supervised. Findings during observation are discussed at this stage. The schools/teachers are commended where necessary and areas of weaknesses are brought into focus for improvement. Suggestions/recommendations are made for improvement.

\section{Problems of School Management and Supervision}

Some of the recurring problems in the management of schools, which are general to almost all the levels of education in the country, are:

i. Inadequate funding

ii. Poor infrastructure

iii. Poor teaching/learning facilities

iv. Low morale of staff

v. Politics

vi. Poor planning

vii. Implementation problems

viii.Inexperience personnel (Supervisors)

ix. Inconsistency in government policies

\section{The Way Out}

a. The Ministries of Education and Proprietors of schools should ensure that only qualified teachers are employed. Head teachers should have basic qualification in educational administration.

b. There should be at least two Vice Principals in every secondary school. These personnel will help the Principal in his/her administrative duties so that more attention is given to supervision.

c. Both public and the private schools should think of how to generate more revenue without increasing school fees arbitrarily in order to facilitate the provision of some basic education facilities for learning. This will enhance the functions of the supervisor.

d. Principals or supervisors should be sponsored to attend refresher courses in school administration to be abreast with current best practices. Conferences, seminars, workshops, etc. are usually quite helpful.

e. School managers and supervisors should focus their functions based on constructive analysis and the reinforcement of successful patterns rather than 
on the condemnation of unsuccessful patterns. (Most supervisors often indulge in fault finding and negative feedback rather than been corrective).

f. School supervisors should not be feared or seen as constituting a threat. (Most teachers still entertain fear at the visit of school inspectors and supervisors).

g. Supervisors should try not to be teacher of teachers but rather help teachers to become co-supervisors. This is likely to result in a change of behaviour of the teachers. When this happens, the teachers and supervisors are likely to have common responsibility as colleagues for the improvement of teaching and learning.

\section{Conclusion}

In this discussion, we have examined the twin concepts of school management and supervision, and found that effective school management and supervision are focused on improving the teaching competence and general well being of the school system. This invariably impacts positively on students' achievement and educational development of the society. Without proper school management and supervision, the rationale for effective instructional services in the schools is therefore underscored. Unfortunately, the inadequacies of effective school management and supervisory practice in the country generally have been revealed, given the dearth of qualified personnel and other education facilities to enhance teaching and learning. This therefore makes a strong case for the school supervisory network championed by the head teachers as partners in progress. In doing this, the paper has emphasized clinical supervision and effective administration of schools by the various head teachers, which if properly done will actualize the primary objective of the school- effective teaching and learning.

\section{References}

Akinade, E. A. (1996). Leadership and motivation: The role of staff in discipline. Ibadan: Caltop Publishers.

Campbell, R. F., Bridges, E. M. \& Nystrand, R.O. (1977). Introduction to educational administration. Allyn and Bacon Inc.

Goldhammer, R. \& Krajeweski, R. J. (1969). Clinical supervision: Special methods for the supervision of teachers. New York: Holt, Reinhart and Winston.

Jaiyeoba, A.O. (2003). Perspective in school administration. In Babalola, J.B. \& Adedeji, S. O. (Eds.) Contemporary issues in educational management: A book of honour. Ibadan: Awemark Industrial Printer. 
Jaiyeoba, A. O. (2006). School administration and supervision. In Babalola, J. B., Ayeni, A. O., Adedeji, S. O., Suleiman, A. A. \& Arikewuyo, M. O. (Eds.) Educational management: Thought and practice. Ibadan: Codat Publications.

Nnabuo, P. O. M. (1996). Supervision and inspection: A humanistic approach. Port Harcourt: Bengray Publications.

Sidho, K.S. (2002). School organization and administration. New Delhi: Sterling Publishing Limited.

UNESCO (2012). Education webmaster: World conference on higher education framework and action, www.jyu/fi/unesco2003/conference.htm (14/09/2013). 